\title{
Microfluidic Paper-Based Analytical Devices (MPADS) in Modern Analysis
}

\author{
Hobbs Bower Reang, Gagandeep and Rohit Bhatia* \\ Department of Pharmaceutical Chemistry \& Analysis, ISF College of Pharmacy, India
}

*Corresponding author: Rohit Bhatia, Department of Pharmaceutical Chemistry \& Analysis, ISF College of Pharmacy,

India

\begin{tabular}{|c|c|}
\hline ARTICLE INFO & ABSTRACT \\
\hline Received: May 10, 2021 & $\begin{array}{l}\text { Citation: Hobbs Bower Reang, Gagandeep, Rohit Bhatia. Microfluidic Paper-Based Ana- } \\
\text { lytical Devices (MPADS) in Modern Analysis. Biomed J Sci \& Tech Res 36(1)-2021. BJSTR. }\end{array}$ \\
\hline Published: 幽 May 25, 2021 & MS.ID.005794. \\
\hline
\end{tabular}

\section{Letter}

Most of the analytical tools of the present world are sensitive, effective and efficient in almost all types of analytical studies. But they all generally have one major common disadvantage that most of these techniques require sophisticated equipment that are bulky in size and require qualified personnel for their operation. 'Labon-a-chip' [1] includes small yet efficient and reliable tools that can perform required analytical works on a comparatively smaller scale in a time much less than others. $\mu$ PADs are one such tool that incorporates paper as the analytical medium for separation and

analysis (Figure 1). Paper is the most abundant and inexpensive polymeric structure of cellulose available. Paper has micro-porous capillary like networks which are responsible for flow of solvents instead of pumps or electronic power, making paper an ideally usable tool [2]. Also, light-weight and portable paper devices are thus suitable to carry to on-field working and detection. $\mu$ PADs use fabricated paper devices on which hydrophilic zones are formed within hydrophobic barriers. Hydrophilic zones act as regions for actual analytical purposes whereas hydrophobic zones act to demarcate separate zones from one another.

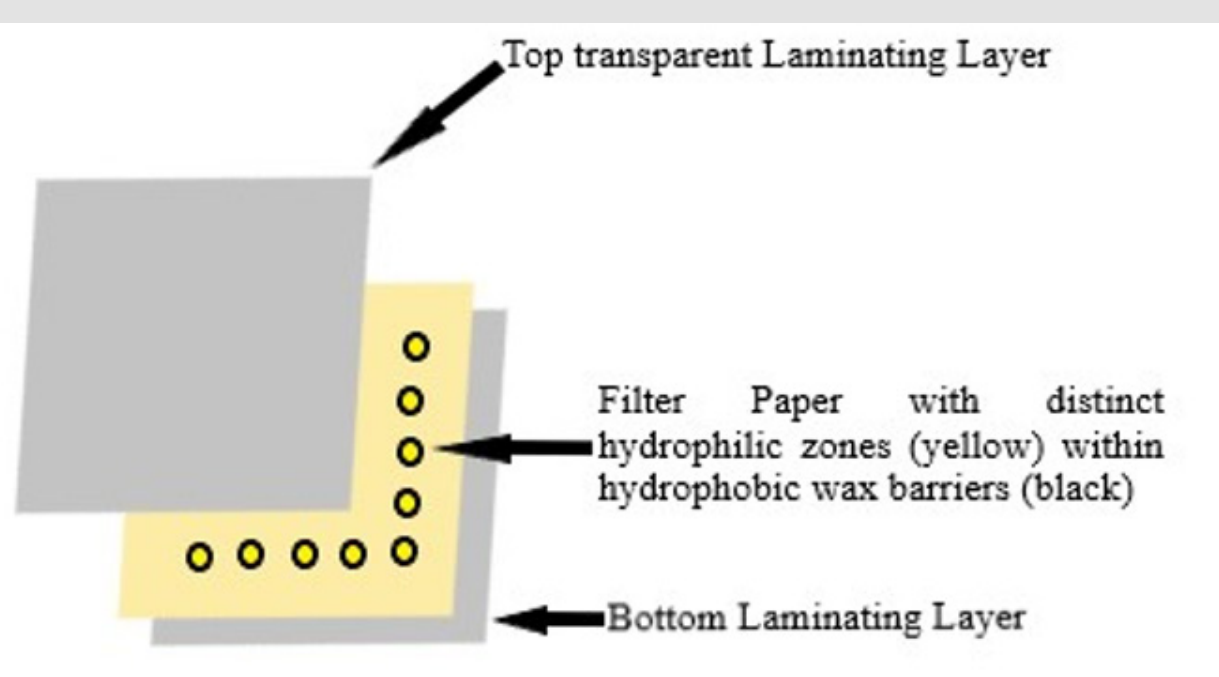

Figure 1: Schematic diagram of paper based analytical device. 
Fabrication of $\mu$ PADs can be done by various methods such as Wax Printing, Wax Dipping, Drawing, Photolithography, Polydimethylsiloxane plotting, Inkjet Printing, Cutting and Plasma Etching [3-6]. Detection methods involve Colorimetric [7,8], Electrochemical [9] as well as fluorimetric [10] approaches. In Colorimetric approaches, color is produced either due to reaction of reagents on the paper with sample in the solvent. Intensity of color is noted which is indicative of concentration of desired analyte under study. Intensity can be noted using Scanners, Digital Cameras or simply Smartphone Cameras and processed using Adobe Photoshop.

Pena-Pereira, et al. in 2016 [11] devised a method for thiocyanate detection in human saliva to be used as a biomarker for expecting tobacco smoke exposure using $\mu$ PADs. The assay incorporated use of formation of an iron(III)-thiocyanate colored complex with colorimetric determination using a scanner. The detection limit was concluded to be $0.06 \mathrm{mM}$ of thiocyanate and Relative Standard Deviation was 3\% for the method. Ortiz-Gomez, et al. in 2016 [12] developed a method for nitrite determination in samples chemically using paper-based devices and colorimetric sensing techniques.

Cellulosic paper was used as medium for detection where nitrite in sample was converted in nitrous acid which as a result converted s-dihydrotetrazine by oxidation to 1,2-dihydro-3,6bis(3,5-dimethyl-1H-pyrazol-1-yl)-1,2,4,5-tetrazine (DHBPTz). This changes detection zone int pink which is analyzed for intensity using a smartphone camera for quantitative purposes. The group applied this method for determination of nitrites in water and limit of detection was found to be $1.30 \mu \mathrm{M}$ for nitrites. They concluded that $\mu$ PADs were stable for 21 days when stored away from heat and light. Later in 2018, Sununta, et al. [13] developed a similar simple, low cost yet effective method for detection of creatinine in urine. The group used principles of Jaffe reaction which involves reaction between creatinine and picric acid which forms colored complex under alkaline conditions. These colored complexes are easily detectable using colorimetry. Under optimized conditions linearity range of 0.2 to $1 \mathrm{mM}$ was achieved with LOD and LOQ of 0.08 and $0.26 \mathrm{mM}$ respectively. The accuracy of results was in compliance with Jaffe's method and thus this method was used for determination effectively. Liu, et al. in 2018 [14] developed a colorimetric assaying method for dopamine in a wide range of samples such as cow serum, human serum and human plasma.

The methodology for detection involved redox reaction between dopamine and ferric chloride reducing Fe3+ to Fe2+ which as a result converts phenanthroline into red colored tris(1,10phenanthroline) iron(II) complex. The method used simple, low cost wax printing fabricated paper devices and detection carried out using a phone camera and Photoshop software. This method showed linearity range between 0.527 to $4.75 \mu \mathrm{mol} / \mathrm{L}$ concentration with detection limit of $0.37 \mu \mathrm{mol} / \mathrm{L}$. Relative Standard Deviation was found to be $0.11 \%$ and $0.15 \%$ for inter-day and intra-day studies respectively. Another group reported a method for colorimetric detection of hydrogen peroxide and glucose in samples using starch-iodide-gelatin system as color producing system [15]. Linear results were obtained between 0.5 to $5 \mathrm{mM}$ of glucose and 0.5 to $6 \mathrm{mM}$ of hydrogen peroxide with LOD of $0.05 \mathrm{mM}$ and $0.1 \mathrm{mM}$ respectively. Recovery values of glucose in real human serum samples were found between $95.7 \%$ to $97 \%$ using this method. The method was found to be quick, sensitive, accurate and reproducible and can be easily carried in resource limiting areas. In a nut shell, it can be concluded that paper based analytical devices may serve as an excellent tool in variety of analytical works. These techniques are simple, rapid, economic and require less human power or trainings. Continuous exploration of these techniques is in progress in various fields of science.

\section{References}

1. Li XJ, Zhou Y (2013) Microfluidic Devices for Biomedical Applications. $1^{\text {st }}$ (Edn.), Woodhead Publishing.

2. Dou M, Sanjay ST, Benhabib M, Xu F, Li X (2015) Low-cost Bioanalysis on Paper-based \& its Hybrid Microfluidic Platforms. Talanta 145: 43-54.

3. Nurak T, Praphairaksit N, Chailapakul O (2013) Fabrication of paperbased devices by lacquer spraying method for the determination of nickel(II) ion in waste water. Talanta 114: 291-296.

4. Songjaroen T, Dungchai W, Chailapaku O, Laiwattanapaisal W (2011) Novel, Simple and low-cost alternative method for fabrication of paperbased microfluidics by wax dipping. Talanta 85(5): 2587-2593.

5. Malekghasemi S, Kahveci E, Duman M (2016) Rapid and alternative fabrication method for microfluidic paper based analytical devices. Talanta 159: 401-411

6. Jiang X, Fan ZH (2016) Fabrication and Operation of Paper-based Analytical Devices. Annu Rev Anal Chem 9(1): 203-222.

7. Li MS, Cao R, Nilghaz A, Guan LY, Zhang XW, et al. (2015) “Periodic-TableStyle" paper device for monitoring heavy metals in water. Anal Chem 87(5): 2555-2559.

8. Ratnarathorn N, Chailapakul O, Henry CS, Dungchai W (2012) Simple silver nanoparticle colorimetric sensing for copper by paper-based devices. Talanta 99: 552-557.

9. Cuartero M, Crespo GA, Bakker E (2015) Paper-based thin-layer coulometric sensor for halide determination. Anal Chem 87: 1981-1990.

10. Chen PC, Li YC, Ma JY, Wang JY, Chen CF, et al. (2016) Size tunable copper nanocluster aggregates and their application in hydrogen sulphide sensing on paper based devices. Sci Rep 6: 24882.

11. Pena Pereira F, Lavilla I, Bendicho C (2016) Paper-based analytical device for instrumental-free detection of thiocyanate in saliva as a biomarker of tobacco smoke exposure. Talanta 147: 390-396.

12. Ortiz Gomez I, Ortega Munoz M, Salinas Castillo A, Alvarez Bermejo JA, Ariza Avidad M, et al. (2016) Tetrazine-based chemistry for nitrite determination in a paper microfluidic device. Talanta 160: 721-728.

13. Sununta S, Rattanarat P, Chailapakul O, Praphairaksit N (2018) Microfluidic Paper-based analytical devices for determination of Creatinine in urine sample. Anal Sci 34(1): 109-113.

14. Liu C, Gomez FA, Miao Y, Cui P, Lee W (2019) A colorimetric assay system for dopamine using microfluidic paper-based analytical devices. Talanta 194: 171-176.

15. Liu M, Lian X, Liu H, Guo Z, Wang H, et al. (2019) A colorimetric assay for sensitive detection of hydrogen peroxide and glucose in microfluidic paper-based analytical devices integrated with starch-iodide-gelatin system. Talanta 200: 511-517. 
ISSN: 2574-1241

DOI: 10.26717/BJSTR.2021.36.005794

Rohit Bhatia. Biomed J Sci \& Tech Res

(c) (P) This work is licensed under Creative BY Commons Attribution 4.0 License

Submission Link: https://biomedres.us/submit-manuscript.php

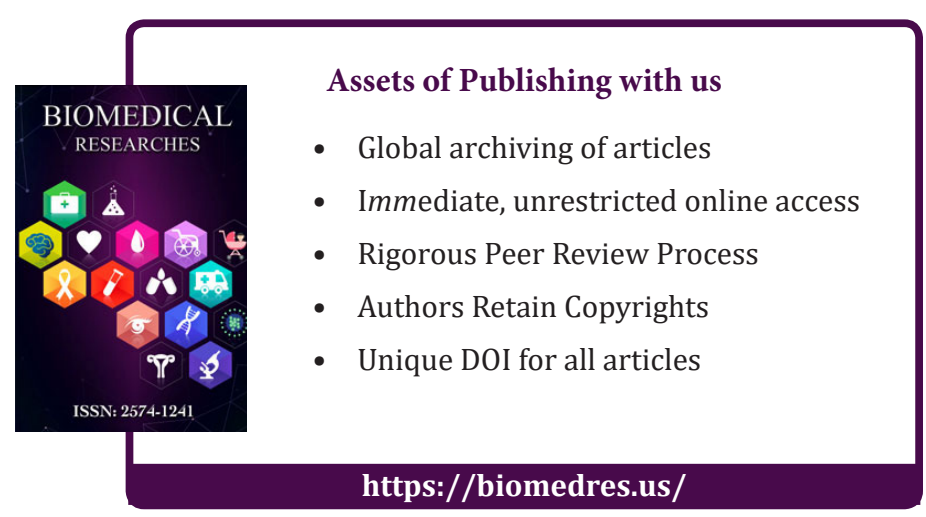

